\title{
The Mnemonic Keyword Method: Effects on the Vocabulary Acquisition and Retention
}

\author{
Vanlee Siriganjanavong ${ }^{1}$ \\ ${ }^{1}$ Language Institute, Thammasat University, Thailand \\ Correspondence: Vanlee Siriganjanavong, Language Institute, Thammasat University, Rangsit Campus, Thailand. \\ Tel: 66816213033. E-mail: S_Vanlee1@yahoo.com
}

Received: July 9, 2013 Accepted: July 30, 2013 Online Published: September 4, 2013

doi:10.5539/elt.v6n10p1 URL: http://dx.doi.org/10.5539/elt.v6n10p1

\begin{abstract}
The objectives of the study were to introduce the technique called "Mnemonic Keyword Method (MKM)" to low proficiency English learners, and to explore the effectiveness of the method in terms of short-term and long-term retention. The sample was purposefully drawn from one intact class consisting of 44 students. They were first-year university students studying a non-credit English remedial course. The materials used in the study consisted of 40 target words, with half of them taught using MKM and the other half with mixed methods, namely contextual clues, word structure analysis, and opposite word-pairs. Students' retention was measured by using a 40-item-vocabulary test and two cued-recall sheets. The results from the vocabulary test and the cued-recall sheets showed that compared to those mixed methods, words taught by MKM could be better recalled both in short-term and long-term memory.
\end{abstract}

Keywords: mnemonic, keyword method, mnemonic keyword method, vocabulary learning strategy, vocabulary retention

\section{Introduction}

Although English is considered a foreign language in Thailand, many educators, scholars as well as learners, have placed great importance on it as it is regarded as an important tool to obtain a better career and higher achievement in the workplace. The majority of Thai learners have learned English since Prathom 5, comparable to Grade 5, if not earlier in Prathom 1 or Grade 1. By the time they reach tertiary education, they have studied English for at least 8 years. It is expected that they have enough knowledge to cope with English studies at university. However, in reality some of these students, despite studying English for many years, still struggle when trying to use or understand the language. They obtained a very low score in English tests as shown by the mean scores of the Ordinary National Educational Test (O-Net), which were 21.51, 19.22, and 21.8 out of 100 in the years 2009, 2010, and 2011 respectively. As a result, some universities have arranged English remedial courses to prepare them for advanced English courses. One factor accounting for the substandard scores of these students could be their lack of vocabulary knowledge.

To enhance students' ability in remembering or acquiring new words, vocabulary learning strategies should be taught (Sagarra \& Alba, 2006). Celce-Murcia (2001; as cited in Amiryousefi \& Ketabi, 2011, p.178) asserted that "strategies can help learners both in discovering the meaning of the words, and consolidating it, and are specially needed when they are encouraged to learn independently." Storing a large number of new words into our memory is a challenging task. Many scholars and researchers have been trying to seek the best method in achieving the goal. One alternative technique that has long been employed to boost reminiscence since the ancient Greek era is a mnemonic method. According to Solso (1995; as cited in Pillai, 2004), mnemonics are techniques or devices, either verbal or visual, which can be utilized to increase a learner's capacity to memorize and recall new information.

Many teachers have tried to find ways to motivate students to learn more vocabulary, and the keyword method might be the answer. In order to prove the effectiveness of the technique in various circumstances and show how the technique helps learners retain the words in their memory, a great deal of studies have been conducted (e.g., Amiryousefi \& Ketabi, 2011; Brown \& Perry, 1991; Sagarra \& Alba, 2006; Shapiro \& Waters, 2005). Some studies required the subjects to make their own imagery linkage between the sound in L1 and L2, while some were teacher-oriented. However, most of the reviewed studies were involved with vocabulary acquisition in 
Spanish (Gruneberg \& Pascoe, 1996), Russian (Sagarra \& Alba, 2006), or other languages such as Egyptian (Brown \& Perry, 1991), with quite a few studies conducted with Thai learners, using Thai words as keywords. In this study, the mnemonic keyword method (MKM) was used because the researcher wanted to provide all learners with the same picture, instead of having them create their own images, each of which might have different effects on memory. The MKM would provide them with both verbal mnemonic and visual mnemonic; that is, pictures and short phrases or sentences with the keywords and their meanings were displayed in the presentation. Using a picture with the linkage of sounds between two languages would stimulate learners' interest and enthusiasm to learn and memorize new words.

Therefore, the purposes of the study are to introduce the technique called "Mnemonic Keyword Method (MKM)" to native Thai EFL learners, and to explore the effectiveness of the method in terms of short-term and long-term retention with the aim of answering the following research questions:

1) Are there any significantly different effects between the two treatments: the MKM and mixed methods?

2) Can the mnemonic keyword method help increase both short term and long term retention of the newly learned words?

\section{Literature Review}

\subsection{The Importance of Vocabulary Knowledge and Vocabulary Learning Strategies}

Vocabulary has been regarded as one of the most important factors in language learning as can be seen from David Wilkins's strong claim cited in Thornbury (2002, p. 13) that "Without grammar very little can be conveyed, without vocabulary nothing can be conveyed." However, knowing a word is beyond knowing merely its form and meanings; that is learners should have other relevant knowledge about that particular word, such as its grammatical functions, and pronunciation (McCarthy \& O'Dell, 1999). Thornbury had a very similar idea on that, and he claimed that learners should also know word collocation, its connotation, and cultural meaning of the word. In addition, he noticed that many learners tend to know a word receptively, but not productively.

According to Schmitt (1997; as cited in Takač, 2008), vocabulary learning strategies are divided into five main types. The first type is determination strategies in which learners analyze the word's meaning by looking at its structure, and parts of speech. The second one is social strategies where learners interact with others to find the meaning such as asking a teacher, a friend, or a native speaker for translation or meaning. The third type which is related to mnemonic approach is memory strategies. Learners will try to memorize the information by relating it to their own experience or images, grouping words with the same meaning together, and so forth. Repetition either orally or by writing, taking notes in class, and labeling things are categorized as cognitive strategies, the fourth type. The last one is metacognitive strategies which include self-testing, skipping unknown words and enhancing vocabulary knowledge by using L2 media. Numerous research studies were conducted to find the most effective way to acquire words, and various strategies, including contextual clues, word analysis, semantic mapping, rote rehearsal, keyword, or a combination of these, were applied as the variables. The findings of some studies supported that subjects who use various strategies in learning words could perform better (Lawson \& Hogben, 1996; Rodiguez \& Sadoski, 2000).

With regard to vocabulary instruction, many teachers seemed to have a strong presumption in favor of contextual clues. It is believed that students would reduce their dependency on dictionaries by this method. Some researchers (e.g., Nagy, Herman \& Anderson, 1985; Nuttall, 1996) asserted that learners who employ contextual clues while reading could learn the words little by little. In other words, it created an incremental knowledge if those words were repeatedly found in other contexts. However, some researchers (e.g., Kelly, 1990; Schatz \& Baldwin, 1986) raised a question on the effectiveness of this strategy due to the fact that guessing the word's meaning from context seemed to be useful and appropriate for strategic readers who are flexible and able to use different techniques while reading. In contrast to those readers, poor readers seemed to struggle not only with the target words but also with the surrounding context because of their limited vocabulary. Failure to use contextual clues, therefore, indirectly denotes the importance of having a large vocabulary bank.

Despite realizing the significance of vocabulary knowledge, there are still some arguments concerning the vocabulary size that learners should possess. For example, Thornbury (2002) stated that readers should have vocabulary knowledge of at least 2,000 high frequency words so as to comprehend $90 \%$ of everyday text. Na and Nation (1985) argued that learners who know 2,000 common words would know approximately 80 percent of the reading text. They will, therefore, encounter one unknown word in every five words, leading to failure in using contextual clues. Laufer (1992; as cited in Saitakham \& Syananondh, 2004) specified that EFL students should have a vocabulary bank of 3,000 common words at university level and 5,000 words for academic 
learning. Those numbers seemed to be small comparing with the numbers suggested by Nation (2006), who claimed that knowing 8,000-9,000 word families are necessary for those who want to read and comprehend authentic written texts, and knowing 6,000-7,000 word families for spoken text. In opposition to these views, Kelly (1990) commented that it is not appropriate to specify the threshold of words that learner should know, as that would lessen the importance of vocabulary learning. As evidenced by these researchers' suggestions, both teachers and students should pay a lot of attention on vocabulary because limited vocabulary knowledge might lead to poor performance on every skill, especially reading.

\subsection{Theoretical Background}

According to the Multi-store Model (Atkinson \& Shiffrin, 1968), input data will flow through three levels of memory. First, it will pass our sensory organs and enter our sensory memory, holding the data for only a few seconds. If we pay attention to the data, it will then pass onto the short term memory. Then if the data is rehearsed and recalled, it will be stored in the long-term memory. Forgetting occurs along the process either because of displacement of information or inattentiveness. Thornbury (2002) supported that attention or arousal is required when learning vocabulary as can be proven by the fact that people can remember swear words well, though having heard them only a few times. He also added that "words that trigger a strong emotional response, for example, are more easily recalled than ones that don't (p. 25)."

Apart from finding effective ways to store newly learned information, teachers should also take into consideration that students have different learning styles and that they have their own preference in acquiring information. According to Fleming's VARK Model (2001), learners are categorized into four different learning styles: visual, auditory, reading/writing, and kinesthetic. Those who are categorized as visual learners like to learn through their eyes, such as seeing pictures, graphs, maps, and so forth, while auditory learners prefer to learn through their ears, including listening to lectures, songs, or people's discussions. Some learners are more likely to learn better through reading and writing. For example, they might prepare themselves by reading a textbook before class, and reviewing it after class, or they might prefer to take notes while studying. For those kinesthetic learners, they will learn better with experiments or through their own experience. Therefore, various media and methods should be used in class so as to attract different types of learners and facilitate them in acquiring new knowledge.

Although there are many kinds of mnemonic approaches, the one that has long been used to teach vocabulary is called the keyword method by Atkinson in 1975. The method has been investigated ever since for its effectiveness in helping learners retain newly learned words in their memory. It is a two-step-approach used especially for learning new foreign words. Firstly, learners need to make an acoustic link between a familiar word in L1 and the target word in L2, which are sound-alike. Then learners create some imagery link between the two. For example, when learning a Spanish word "pato," which means duck, and is pronounced as /pot-o/. The keyword in English is "pot," which sounds like the original word in Spanish. To link the sound with its meaning, a learner needs to imagine "a duck hiding their head under an overturned pot." In this way, they can supposedly better memorize the word and its meaning because they relate the new information to existing knowledge. Consequently, the new word can be retained in memory for a longer time. The strategy appears to be in line with the Depth-of-Processing Theory by Craik and Lockhart (1972). According to the theory, learners require a deep level of processing in order to retain new information in their memory. In other words, how deeply the information is cognitively triggered and processed affects the incorporation of prior knowledge and newly learned information being transferred into long-term memory. Their theory also pointed out that elaboration at all levels would enhance memory above at any one level alone.

Shapiro and Waters (2005) asserted that the superiority of the keyword method lies on the fact that visual images are considered strong stimuli for the human brain. Likewise, Amiryousefi and Ketabi (2011) believed that new words would be learned if they were combined with pictures. Not only can pictures facilitate recall, but they can also increase learners' motivation and interest. Pictures in this aspect can be the real pictures or the visualized images.

\subsection{Research on the Effectiveness of the Keyword Method}

Many research studies were conducted to find out how the keyword method could help students acquire new words and retain those words in long-term memory. Brahler and Walker (2008) divided their subjects into three groups; the keyword method, rote memorization, and the combination of both. The findings revealed that students in the keyword group could significantly outperform the other two groups in terms of recall. In other words, the keyword group could remember the medical terminology better than those in rote memorization group or the mixed method group. The keyword method works well not only for young learners, but also for the elderly as 
evidenced by Gruneberg and Pascoe's study (1996). They found that 40 female elderly subjects who had a mean age of 70.45 could significantly improve their receptive and productive learning of 20 Spanish words, compared with a control group who received no treatment.

Some studies (e.g., Brown \& Perry, 1991; Sagarra and Alba, 2006; Wang \& Thomas, 1995) focused on the effects of the method over time by using the immediate and the delayed tests. In Brown and Perry's study (1991), the findings revealed that students in the keyword group gained a higher score in the immediate test, and the effect was greater with low-proficiency students, while the students in the combined keyword-semantic strategy could retain the words better than using either one strategy alone in the 9-day delayed test. Similarly, the keyword group in Wang and Thomas's study (1995) also performed significantly better than the other group (semantic-context strategy) in the immediate test. However, the semantic-context group could produce better performance in the 2-day delayed test. When incorporating practices into the experiment, the keyword group showed the tendency to retain the words better than the semantic-context group, implying that repeating tests and rehearsal are necessary in order to enhance the effect of the keyword method in the long run. In contrast to the aforementioned studies, Sagarra and Alba (2006) found different outcomes. With regard to short term retention, the keyword learners outscored the rote memorization in which learners studied the new words with their L1 translation, and the rote memorization group outperformed those learning by semantic mapping, in which L1 words relating to the L2 word were presented in a diagram. With respect to long term retention, the scores from the 3 -week delayed posttest showed that the lowest one was from semantic mapping (31\%), followed by rote memorization $(26 \%)$, and the keyword method (23\%).

\section{Methodology}

\subsection{Participants}

The population selected consisted of low proficiency EFL learners who enrolled in a non-credit English remedial course at Thammasat University, Thailand. Their entrance scores (O-Net) in English ranged from 10-25, with the mean score of 19.6 out of 100 . As a result, they were defined as low proficiency students. The sample group was purposefully drawn from one intact class, which initially consisted of 44 students. They were all first year students from the Faculty of Science and Technology. Only students who participated in every process were included in the statistical analyses of the study. At the final stage, there were altogether 37 participants since seven students missed some classes.

\subsection{Materials}

The main materials in the study consisted of forty target words selected by considering the syllable length and their frequency level. The mean length of syllables taught by MKM was 2.75, and those taught by mixed methods was 2.61. The selected words were of various frequency levels ranging from high frequency ones such as consent, venture, and contribute to low frequency ones such as divulge, emulate and jeopardy. However, the mean frequency level of the words taught were at a similar level $(\mathrm{MKM}=4246.8$, Mixed Methods $=4178.1)$ based on the Corpus of Contemporary American English (COCA). In addition, a multiple-choice vocabulary test consisting of 40 items was used to measure students' scores before and after the treatment. The test was piloted with 48 students who were of a similar proficiency level. The results showed that the mean difficulty level of the first 20 words expected to be taught by MKM was 0.24 , while another 20 words expected to be taught with mixed methods was 0.33 . It could be implied that the second group of the words was a bit easier. One possible explanation could be that these students had some background knowledge about contextual guessing and word structure analysis. To assess students' short term retention, two cued-recall sheets in which students were required to complete the words' meaning(s) or synonym(s) were distributed in week 2 and week 3 at the end of each class hour that the new words were taught.

\subsection{Procedures}

First, the vocabulary pre-test was distributed in week 1 . Then the researcher presented twenty target words in two consecutive weeks (weeks 2 and 3) of the normal class hours. Each presentation took approximately 15-20 minutes. In the first presentation, the researcher started with a short introduction of what mnemonic keyword method is, along with its advantages. Also, the subjects were informed that these vocabulary words would not be evaluated in the midterm or the final exam. However, these words would be beneficial for them as they were likely to appear in academic texts or news articles. Twenty words were presented at the beginning of each class before the normal lesson, with half of them taught by MKM, and another half by mixed methods including word structure analyses, contextual clue guessing, and opposite word-pairs.

Two examples of MKM presented with a PowerPoint can be seen below. For the word "amendment," the 
synonyms - change, adjustment, improvement - were written in the arrow along with its meaning in L1. "Ah!..mend...ment" which means "Ah! What a stink!" acts as a keyword. "Ah" is an interjection word in Thai, and "mend" means smelly, the word is used twice with the rising tone to mean "very." Then it was linked with the meaning in the phrase "Go get changed." For the word "culprit," its synonyms and meanings were also provided in the arrow. Surprisingly, the keyword "kao-pid" in L1 has a very similar sound and meaning to the newly learned word "culprit." In Thai, "kao" acts as either a $2^{\text {nd }}$ or $3^{\text {rd }}$ personal pronoun representing either male or female, and "pid" means wrong, incorrect, or mistake. Therefore, "kao-pid" was interpreted as "he is the criminal."

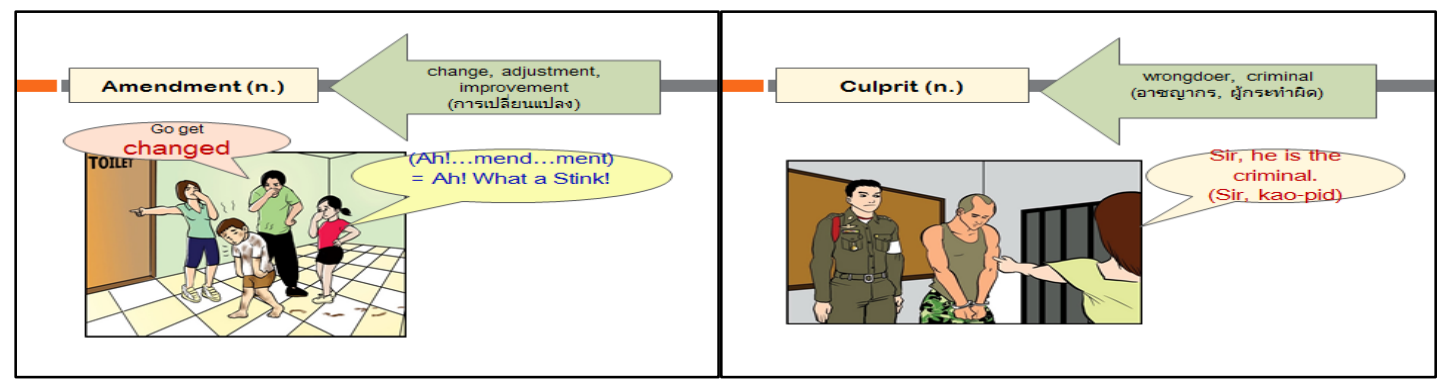

Following the presentation of 20 words in each week, a cued-recall sheet was distributed requiring students to fill in the word meaning in Thai or its English synonym(s). The purpose of giving them a cued-recall sheet was to test their ability to retrieve the target words, or to measure their short-term retention. The words shown in the recall sheet were rearranged to avoid the effect of remembering words or their meanings in order. All the forty target words were reviewed in week 4 so as to avoid differential time effects between those taught in week 2 and week 3. No treatment or test was given in week 5. However, the subjects were required to do the post-test in week 6 without being informed in advance of the test.

Scoring: Answers appeared on the cued-recall answer sheet were checked according to the following criteria. One point will be rewarded for any correct meaning in Thai or synonym in English. Half a point was given if the subjects wrote one correct answer and one wrong answer for the same item.

\section{Results and Discussion}

The results and discussion of the study are divided in two main parts, with the first part focusing on the first question whether there are any significantly different effects between the MKM and mixed methods. Following that, the second part will answer the question whether the MKM can help increase both short term and long term retention of the newly learned words.

\section{Part 1}

To compare the effectiveness of the teaching methods, the scores from the multiple-choice test consisting of 40 items were divided into two sections: the first half and the second half. The words taught by MKM were in the first half, while the second half consisted of the words taught by the mixed methods.

Table 1. Means and standard deviations from the pre-test and the post-test according to the different teaching methods

\begin{tabular}{llllll}
\hline & M & SD & Std. error mean & t-test & Sig. \\
\hline Pre-test (MKM) & 5.35 & 1.62 & .27 & 8.06 & $.000^{* * *}$ \\
& & & & & \\
Post-test (MKM) & 9.89 & 3.22 & .53 & .32 & $.025^{*}$ \\
Pre-test (Mixed Methods) & 6.22 & 1.95 & .32 & & \\
Post-test (Mixed Methods) & 7.22 & 2.65 & .44 & & \\
\hline
\end{tabular}

$n=37, * * * p \leq .001,{ }^{*} p \leq .05$

The mean scores that the subjects received in each section both in the pre-test and post-test are provided in Table 1. It can be seen that prior to the treatments, the mean score from the section expected to be taught with the MKM was lower than the section expected to be taught with mixed methods ( $\mathrm{MKM}=5.35$, Mixed Methods $=6.22)$. However, after the treatments, the mean score increased to 9.89 points with the MKM $(\mathrm{t}(36)=8.06, \mathrm{p} \leq .001)$, while the 
subjects received only 7.22 points in their mean score with mixed methods $(\mathrm{t}(36)=2.35, \mathrm{p}<.05)$. The $\mathrm{t}$-test results revealed that the subjects could significantly enhance their vocabulary knowledge by both treatments, but MKM $(\mathrm{t}(36)=8.06, \mathrm{p} \leq .001)$ seemed to have a greater effect than mixed methods $(\mathrm{t}(36)=2.35, \mathrm{p} \leq .05)$.

Table 2. The increase in mean scores from the post-test comparing between words taught by MKM and mixed methods

\begin{tabular}{llllll}
\hline Methods & M & SD & Std. error mean & t-test & Sig. \\
\hline MKM & 4.54 & 3.43 & .56 & 5.01 & $.000 * * *$ \\
& & & & & \\
Mixed Methods & 1.00 & 2.59 & .43 & &
\end{tabular}

Table 2 revealed the differences in the increase in mean scores from the post-test with different methods of teaching. Students could increase their performance by 4.54 points in the post-test with MKM, while they could have only a one-point-increase with mixed method. The t-test result showed that the rising score from the MKM was significantly higher than the mixed method at $\mathrm{p} \leq .001(\mathrm{t}(36)=5.01)$. This suggests that learning new words through MKM seemed to be more effective in terms of retention.

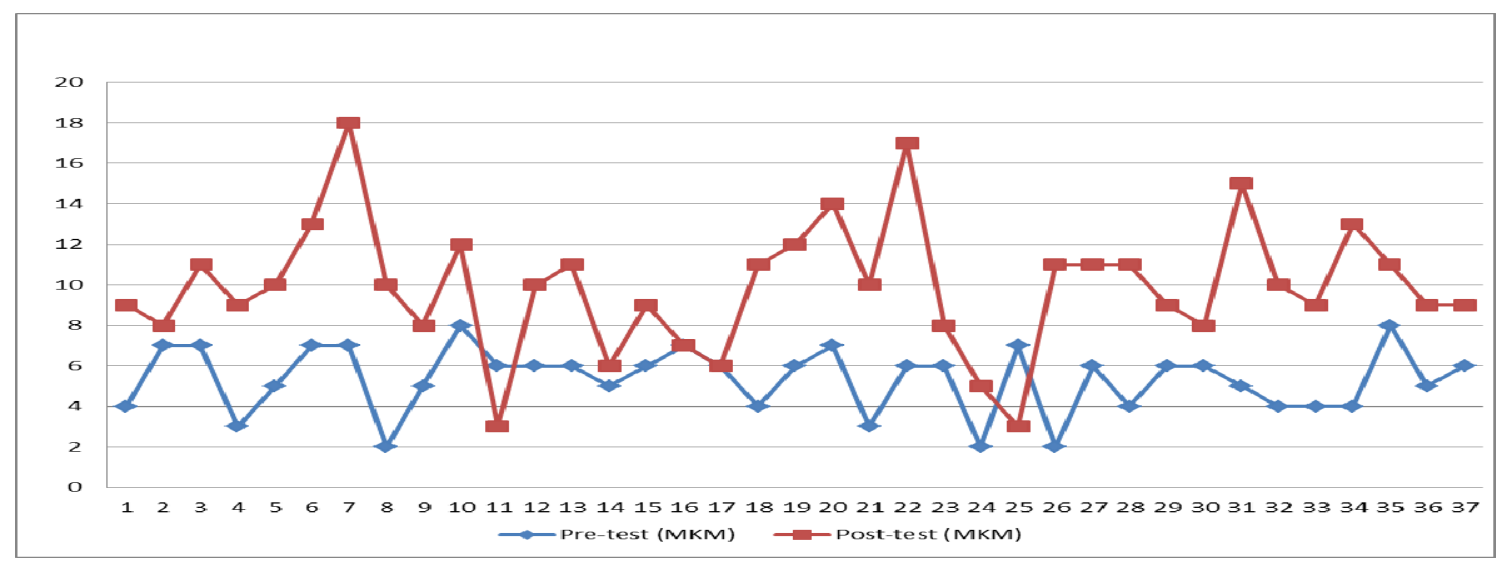

Figure 1. Scores of individual subjects from the pre-test and the post-test using MKM

Figure 1 clearly illustrates that 35 out of 37 students $(94.6 \%)$ could gain an increasing score in the post-test for the words taught by MKM. The greatest effect was found in student No. 7 and student No. 22, who performed obviously better in the post-test; that is, they both received 11 points higher. Apart from those two, student No. 31 also received 10 points higher. However, there were two students (No. 11 and No. 25) who received a lower score in the post-test, which was accounted for $5.4 \%$ of the total population.

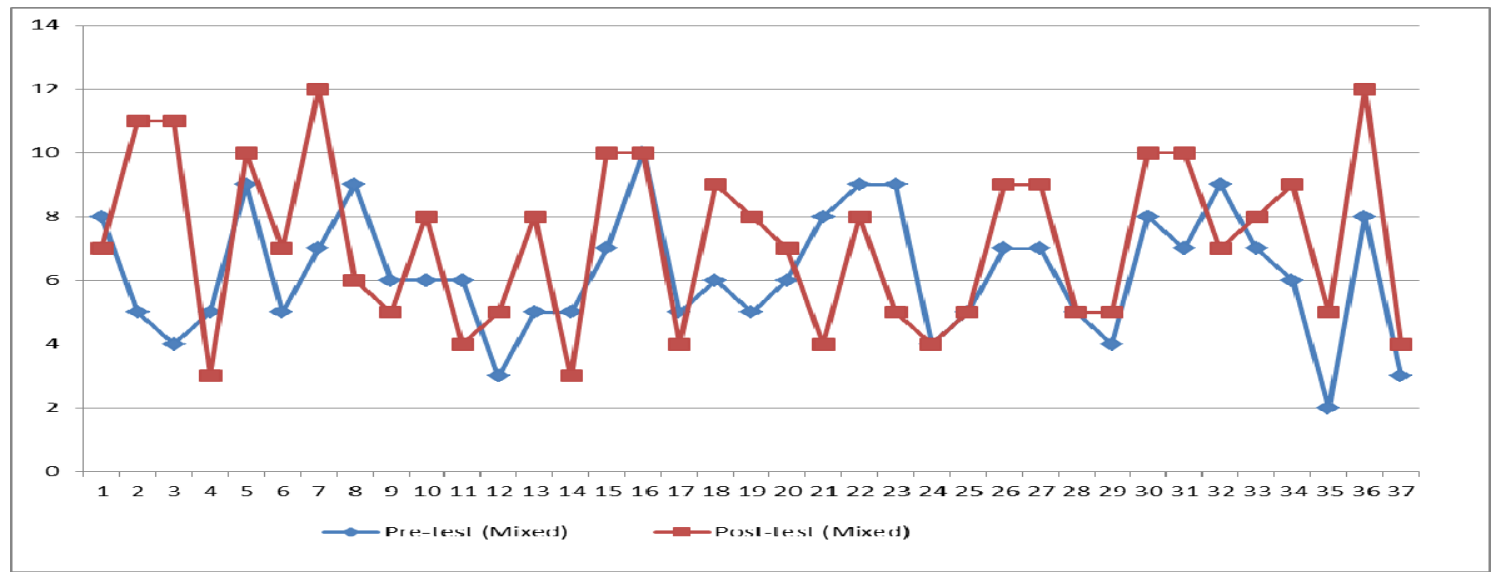

Figure 2. Scores of individual subjects from the pre-test and the post-test using mixed methods 
As can be seen in Figure 2, using mixed methods to teach new words seemed to have a non-consistent effect on students' performance. Although the mean score obtained from the post-test was higher than that in the pre-test, 12 out of 44 students $(27.27 \%)$ received lower scores as can be noticed from the fluctuating line graph when compared with the pre-test scores, and the scores of four students $(9.09 \%)$ remained the same.

There are many possible reasons why the mean score from MKM was generally higher than that of mixed methods. Even considering the individual score, we can see that the majority of the students could gain a higher score when the score was compared with mixed methods. One possible explanation comes from the fact that the MKM matches various styles of learners, apart from facilitating the learners' memory. Based on the VARK Model by Fleming (2001), the teacher-provided-presentation consisted of pictures which were supposed to attract those visual learners and the keyword with a similar sound written in L1 and L2 which might appeal to both auditory and read types of learners. Apart from that, the supplementary sheets were provided so that those prefer writing could take some notes. However, there was no activity for kinesthetic learners who prefer to learn through experience. This might be one reason why those two students received a lower score in the post-test. Educators should be reminded that each learner has their own preferred style of learning; therefore, the teaching styles and media selected to apply in the class should be varied to attract the majority of students and motivate their interest. In contrast, employing only one teaching style for the whole semester could definitely lead to a dull class environment. Additionally, the findings support the Depth-of-Processing Theory (Craik \& Lockhart, 1972) due to the fact that learners who used the MKM have to link the familiar sound in L1 with the new word in L2. In the information processing level, it is believed that the newly learned information will be combined with the pictures, contributing to longer term information retention.

Part 2

To compare the effectiveness of both teaching methods in terms of retention, the scores from two cued-recall sheets were used to measure students' short-term retention, while a 40-item-multiple-choice test previously used as a pre-test was distributed two weeks after the vocabulary revision to assess students' long-term retention. The two cued-recall sheets were distributed on the same day that the vocabulary was taught and they were referred to as the immediate test, whereas the multiple-choice test was given two weeks after reviewing all the 40 words; therefore, it was referred to as the delayed test. The items in the recall sheet and the multiple choice test were not in the same order as the items taught in each week.

Table 3. Mean scores of students from the immediate and delayed test according to the methods of teaching

\begin{tabular}{|c|c|c|c|c|c|}
\hline Methods & $\mathrm{M}$ & $\mathrm{SD}$ & Std. error mean & t-test & Sig. \\
\hline \multicolumn{6}{|l|}{ MKM } \\
\hline immediate & 15.07 & 3.57 & 0.59 & \multirow{3}{*}{-9.83} & \multirow{3}{*}{$.000 * * *$} \\
\hline & & & & & \\
\hline 2-week-delayed & 9.89 & 3.22 & 0.53 & & \\
\hline \multicolumn{6}{|l|}{ Mixed Methods } \\
\hline immediate & 10.07 & 3.37 & 0.55 & \multirow{3}{*}{-5.28} & \multirow{3}{*}{$.000 * * *$} \\
\hline & & & & & \\
\hline 2-week-delayed & 7.22 & 2.65 & 0.44 & & \\
\hline
\end{tabular}

Table 3 reveals that the mean score of the students obtained from the immediate test and the delayed test from different methods of teaching. As regards MKM, the mean score from the immediate test $(\mathrm{M}=15.07, \mathrm{SD}=3.57)$ was higher than the delayed test $(M=9.89, \mathrm{SD}=3.22)$. The t-test showed that the mean score reduced significantly over two weeks $(\mathrm{t}(36)=-9.83, \mathrm{p} \leq .001)$. Likewise, as for mixed methods, the immediate test score $(\mathrm{M}=10.07, \mathrm{SD}$ $=3.37)$ was higher than the delayed test $(\mathrm{M}=7.22, \mathrm{SD}=2.65)$, and the reducing rate was significant $(\mathrm{t}(36)=-5.28$, $\mathrm{p} \leq .001)$. 
Table 4. The decrease in mean scores from a 2-week-delayed test obtaining from the MKM and mixed methods

\begin{tabular}{llllll}
\hline Methods & M & SD & Std. error mean & t-test & Sig. \\
\hline MKM & -5.18 & 3.20 & 0.53 & 3.19 & $.001^{* * *}$ \\
Mixed Methods & -2.85 & 3.29 & 0.54 & & \\
\hline
\end{tabular}

$n=37, * * * p \leq .001$

Table 4 presents the decrease in mean scores from MKM and mixed methods by comparing between the scores students obtained from the cued-recall sheet and the 2-week-delayed post-test. The mean score of MKM (M = $-5.18, \mathrm{SD}=3.20)$ showed the higher decreasing rate than that of mixed methods $(\mathrm{M}=-2.85, \mathrm{SD}=3.29)$. When using one sample t-test to compare the reducing scores between the two strategies, it was found that there was a significant difference in the scores for MKM and other mixed methods ( $\mathrm{t}$-test $=3.19, \mathrm{p} \leq .001)$, suggesting that the rate of forgetting words taught by MKM is higher than those taught with other mixed methods.

The findings were consistent with Brown and Perry's study (1991), which summarized that the keyword method tended to show a greater effect with short-term memory, and it was suitable for low proficiency English learners. In addition, they also found that the effectiveness of the method reduced over time. As implied by Wang and Thomas (1995), to transfer information from short-term into long-term memory, learners need to encompass other methods-rehearsal, retrieval, reading widely, doing vocabulary exercises, and etc.--to make the information fixed into their mind. By using more than one strategy to learn new words, it was found that the words could be better retained and recalled (e.g. Brown \& Perry, 1991; Lawson \& Hogben, 1996; Rodriguez \& Sadoski, 2000). Although the forgetting rate of MKM seemed to be faster than mixed methods, the mean score from MKM was still higher, partly supporting Sagarra and Alba's study (2006), which revealed that the keyword group attained the highest score in both the immediate and the delayed tests, compared with rote learning and semantic mapping.

Apart from the different conditions of immediate and delayed testing time, one possible explanation why most students could obtain a higher score from the immediate test than the delayed test might lie in the different test formats. When noticing from the cued-recall sheet, the researcher found that the majority of students preferred to provide the meanings of the words in Thai, with a few writing their English synonyms as answers. Therefore, they could get higher scores in the cued-recall test where they wrote the answers in their native language, while they got lower score in the multiple choice test where the correct answer and the distractors of each item are all in English. This implies that the effect of linking the sound of L1 and L2 together can enhance learners' retention in memorizing the meaning in L1, and these low-proficiency students did not pay attention in remembering the synonyms of the vocabulary, though the synonyms were also provided both in the presentation and the supplementary vocabulary sheet.

\section{Conclusion and Implications}

This study aimed to introduce the technique called "Mnemonic Keyword Method" to native Thai EFL learners, and explore the effectiveness of the method in terms of short-term and long-term recognition. The study showed that low proficiency EFL students can retain more words both in short-term and long-term with MKM than with other mixed methods, though its effectiveness reduced over time. MKM's superiority might be attributed to the fact that the method combined both verbal and visual aids together, and it also linked the newly learned information to the existing knowledge in our mind.

Some pedagogical implications can be drawn from the study. First, using MKM should be one of the alternatives for teaching hard-to-remember or low frequency words as the findings show that the method can enhance learners' performance in retaining the words in memory. To prevent the new information from fading, teachers might use MKM along with other methods such as asking learners to rehearse new words, do vocabulary exercises, or create a sentence with new vocabulary so as to enable the learners to transfer the information into long-term memory. This was in line with Atkinson and Shiffrin's Multi-store Model (1968), which posited that apart from attention, rehearsal and recall loop were indispensable for maintaining information for a longer time. Second, the distinctiveness of MKM is to enable students to recognize words and their meanings, but its weaknesses can be found regarding pronunciation and spelling. To solve the problems, students should be encouraged to further practice how to accurately pronounce the particular words such as using an online dictionary, and a spelling quiz might be required as a way to stimulate rehearsal. Moreover, some might argue that many words do have multiple meanings, and teaching each word with only one meaning is insufficient. 
However, in the researcher's viewpoint, vocabulary learning involves many steps and recognizing its form and meaning is regarded as the first step. During our childhood when learning a new word in L1, we normally learned one of its meanings at a time, and more meanings were added later. With regard to the word "amendment," teachers might subsequently add more information that the word is a legal technical term. Lastly, teachers might start with a teacher-oriented one, and then let students produce their own MKM, as it is demonstrated by many studies that students could outperform with the self-produced keyword.

There are still a lot to be explored regarding the effects of MKM on vocabulary acquisition. Further studies should be conducted with an increasing number of students, and with different backgrounds to increase the generalizability of the findings. The study needs to be replicated with higher proficiency students to find out whether the MKM yields similar results. As noticed from the cued-recall sheets, the majority of the subjects wrote the word's meaning in Thai, with a few writing its English synonyms. It implies that they prefer to remember new words with its meaning in L1. Assessing students' long-term memory with choices in English might affect students' performance; therefore, the cued-recall sheets might be used once again as the post-test. Moreover, we could not be certain regarding the reason why some students got a lower score with MKM in the post-test unless employing an interview as a tool. This would help confirm the prediction whether those two students were kinesthetic learners or not.

\section{Acknowledgements}

I would like to express my deepest appreciation to all those who provided me with the possibility to complete this research. First, I would like to thank all the students who participated in the study. Without them, the study would not have been possible. Second, I would like to express my gratitude towards many of my colleagues who provided constructive comments on the research tools. My special thanks also go to Zia Collins Free who assisted in proofreading the article. Last but not least, I am indebted to Thammasat University for providing me with funding for the study.

\section{References}

Amiryousefi, M., \& Ketabi, S. (2011). Mnemonic instruction: A way to boost vocabulary learning and recall. Journal of Language Teaching and Research, 2(1), 178-182. htttp://dx.doi.org/10.4304/jltr.2.1

Atkinson, R. C. (1975). Mnemotechnics in second-language learning. American Psychologist, 30(8), 821-828.

Atkinson, R. C., \& Shiffrin, R. M. (1968). Chapter: Human memory: A proposed system and its control processes. In K.W. Spence, \& J. T. Spence (Ed.), The Psychology of Learning and Motivation, (vol. 2, pp. 89-195). New York: Academic Press.

Brahler, C. J., \& Walker, D. (2008). Learning scientific and medical terminology with a mnemonic strategy using an illogical association technique. Advanced Physiology Education, 32, 219-224. htttp://dx.doi.org/10.1152/advan.00083.2007

Brown, T. S., \& Perry, F. L. Jr. (1991). A comparison of three learning strategies for ESL vocabulary acquisition. TESOL Quarterly, 25(4), 655-670.

Craik, F. I. M., \& Lockhart, R. S. (1972). Levels of processing: A framework for memory research. Journal of Verbal Learning and Verbal Behavior, 11, 671-684.

Fleming, N. (2001). VARK A guide to learning styles. Retrieved April 13, 2012, from http://www.vark-learn.com/english/page.asp?p=categories

Gruneberg, M. M., \& Pascoe, K. (1996). The effectiveness of the keyword method for receptive and productive foreign vocabulary learning in the elderly. Contemporary Educational Psychology, 21, 102-109. http://dx.doi.org/10.1006/ceps.1996.0009

Kelly, P. (1990). Guessing: No substitute for systematic learning of lexis. System, 18(2), 199-207.

Lawson, M. J., \& Hogben, D. (1996). The vocabulary-learning strategies of foreign-language students. Language Learning, 46(1), 101-135.

McCarthy, M., \& O’ Dell, F. (1999). Vocabulary in use upper intermediate. Cambridge: Cambridge University Press.

Na, L., \& Nation, I. S. P. (1985). Factors affecting guessing vocabulary in context. RELC Journal, 16(1), 33-42.

Nagy, W., Herman, P., \& Anderson, R. (1985). Learning words from context. Reading Research Quarterly, $20(2), 233-253$. 
Nation, I. S. P. (2006). How large a vocabulary is needed for reading and listening? The Canadian Modern Language Review, 63(1), 59-82. htttp://dx.doi.org /10.3138/cmlr.63.1.59

Nuttall, C. (1996). Word attack skills. Teaching reading skills in a foreign language (pp. 62-64). Oxford: The Bath Press.

Pillai, N. R. (2004). Using mnemonics to improve vocabulary boost memory and enhance creativity in the ESL classroom. Retrieved from http://www.melta.org.my/ET/2004/2004-62.pdf

Rodriguez, M., \& Sadowki, M. (2000). Effects of rote, context, keyword, and context/ keyword methods on retention of vocabulary in EFL classrooms. Language Learning, 50(2), 385-412. htttp://dx.doi.org/10.1111/0023-8333.00121

Sagarra, N., \& Alba, M. (2006). The key is in the keyword: L2 vocabulary learning methods with beginning learners of Spanish. The Modern Language Journal, 90(2), 228-243.

Saitakham, K., \& Syananondh, K. (2004). A study of English vocabulary learning strategies of the third-year English major students of the faculty of Humanities and Social Sciences at Naresuan University. Christian University Journal, 10(2), 122-136.

Schatz, E. L., \& Baldwin, R. S. (1986). Context clues are unreliable predictors of word meanings. Reading Research Quarterly, 21(4), 439-453.

Shapiro, A. M., \& Waters, D. L. (2005). An investigation of the cognitive processes underlying the keyword method of foreign vocabulary learning. Language Learning, 9(2), 129-146. http://dx.doi.org/10.1191/1362168805lr151oa

Takač, V. (2008). Survey of research on vocabulary learning strategies. Vocabulary Learning Strategies and Foreign Language Acquisition (pp. 58-90). Clevedon, UK: Multilingual Matters.

Thornbury, S. (2002). How words are learned. In J. Harmer (Ed.), How to Teach Vocabulary (pp. 13-31). Harlow: Longman.

Wang, A. Y., \& Thomas, M. H. (1995). Effects of keyword on long-term retention: Help or hindrance? Journal of Educational Psychology, 87(3), 468-475.

\section{Copyrights}

Copyright for this article is retained by the author(s), with first publication rights granted to the journal.

This is an open-access article distributed under the terms and conditions of the Creative Commons Attribution license (http://creativecommons.org/licenses/by/3.0/). 